Autor invitado 


\title{
Enunciación
}

http://revistas.udistrital.edu.co/ojs/index.php/enunc

DOI: http://doi.org/10.14483/22486798.12903

AUtOr INVITADO

\section{Si Electra fuese colombiana, se llamaría Rosalba, Ismena, María Eugenia, Vera, Alix María, Patricia, Gloria, Margarita...}

\author{
Marie Estripeaut-Bourjac* \\ Para todas y cada una de las mujeres que sacaron tiempo \\ y energía para contarme su historia.
}

Electra se niega a permanecer en silencio mientras no se le haga justicia y los culpables de la muerte de su padre no reciban su merecido castigo: "Si el desafortunado muerto debiera quedarse tendido, condenado a la nada y al polvo, sin que los demás carguen a su vez con la sangrienta culpa, se acabaría para siempre jamás toda conciencia y toda piedad para los hombres" (Sófocles, 1972, p. 146). Su figura hará las veces de brújula para desentrañar las características de la palabra testimonial femenina, ya que, como Rosalba, quien busca sin descanso el cadáver de su hermano, cifra su dignidad en no callarse y, con ella, clama: "Mi dignidad, mi dignidad vale más que todo lo que se perdió" (Rosalba, citada por Franco, Nieto y Rincón, 2010, p. 105).

Ante la sorprendente cantidad de relatos efectuados por mujeres y en medio de esta efervescencia testimonial que conoce actualmente Colombia, propongo la hipótesis de que esta escritura ${ }^{1}$ reviste para ellas una significación especial. Equivale, en efecto, a salir del marco del diario íntimo, tradicionalmente reservado al yo femenino, para ocupar la escena pública, en un momento significativo de la vida, que exige hacer una pausa. Para una mujer, escribir una autobiografía significa romper el espejo (no se trata del espejo de Lacan, en el cual el niño, cuando puede reconocerse en él, demuestra que está adquiriendo identidad propia, sino de la imagen externa de sí compuesta de los estereotipos y modelos elaborados por una sociedad de tipo patriarcal e interiorizados por las mismas mujeres). ¿Se tratará de ofrecer otro? No, pero sí de construir su identidad, mediante diversas etapas en las que, del espejo roto, se sacan pedazos con el fin de criticarlos o darles vida y contenido propio.

* Profesora titular de español en la ESPE d'Aquitaine-Université de Bordeaux (Francia). Doctora en Estudios Ibéricos y Latinoamericanos de la Universidad de la Sorbona y magíster en Literatura y Lingüística Hispanoamericana en el Instituto Caro y Cuervo (Colombia). Ha publicado L'Écriture de l'urgence en Amérique Latine (Presses Universitaires de Bordeaux, 2012); Palabras de mujeres: proyectos de vida y memoria colectiva (Siglo del Hombre Editores, Bogotá, 2012); con Nicolas Sembel, Femmes, travail, métiers de l'enseignement: rapports de genre, rapports de clase (Presses Universitaires de Rouen et du Havre, 2014); con Dominique Gay-Sylvestre, Mixité et éducation: pratiques sociales et dimensions culturelles (Presses Universitaires de Limoges, 2015); con Maryse Renaud, El mal en la literatura latinoamericana, ( CRLA-Archivos, Université de Poitiers, 2015). Ha publicado también varios artículos sobre las vanguardias latinoamericanas, la escritura testimonial, la escritura del "yo", la memoria y el papel de las artes en la construcción de la paz en Colombia, así como sobre temas de género. Actualmente prepara, como editora, la edición de la jornada de estudios "Laïcité et éducation. Diversité des pratiques en France et ailleurs", así como la publicación de las actas del coloquio internacional "Vérité(s), Réparation(s), Réconciliation(s)". Correo electrónico: estrjac@wanadoo.fr.

1 En otro trabajo (La escritura de la urgencia en América Latina), he llamado escritura del yo a todas las formas que utilizan la primera persona (autobiografía, testimonio, diario, memorias, historia de vida) y cuyo punto común consiste en testimoniar algo. 


\section{LA VOZ}

Electra: “¡Pues bien! Yo no dejaré mis lamentos ni mi lúgubre quejido, mientras siga viendo el resplandor titilante de las estrellas o esta luz del día" (Sófocles, 1972, p. 141).

Llama la atención la importancia que le otorga el yo femenino al hecho de tomar la palabra, lo que induce a plantear que, para las mujeres, adueñarse de su voz es un elemento de la conquista de su identidad y de su autonomía. Para ellas, usar el verbo en público representa, en efecto, transgredir su condición, y lo hacen alzando la voz. Un tipo amenaza a Islena (miembro del Comité Cívico por los Derechos Humanos de Villavicencio) por teléfono: "[...] lo interrumpí. Le contesté peor. Con toda la ira que tenía acumulada le dije todos los insultos que me sabía. [...] Entre más le hablaba, más me envalentonaba" (Rey, citada por Franco, Nieto y Rincón, 2010, p. 119). Apoderarse de su voz significa una liberación, la misma que experimenta Vera Grabe el día que tiene un altercado con Antonio Navarro:

Nunca le había revirado así a un jefe, y nunca había gritado. Por fin había roto una membrana [...]. Cuanto más vociferaba él, más gritaba yo, furiosa, y a la vez le agradecía permitirme soltar una obediencia reprimida y el derecho a opinar diferente. (Grabe, 2000, p. 229)

Esta nueva conducta es producto de una progresiva toma de conciencia de que el uso del poder y la dominación se ejercen mediante conductas y elementos simbólicos, como la voz y el grito. Vera se percata, así, de que para una mujer el espejo construido por la sociedad puede convertirse en una pared que no refleja ninguna imagen, al notar que en las discusiones políticas sus opiniones no tienen ninguna repercusión, hasta tal punto que duda de su capacidad verbal: "Mucho más tarde descubrí que esto es algo que nos pasa con frecuencia a las mujeres: sentirnos invisibles" (Grabe, 2000, p. 80).

Decir "yo" es llegar a ser yo, separar su voz de la de los demás, asumiendo todas las consecuencias para su imagen social y su seguridad. Unir yo a un nombre y a un apellido, para hablar de acontecimientos determinados, tiene también valor jurídico, pero en Colombia conlleva un riesgo que obliga a muchos mediadores a cambiar el apellido de los testigos. El yo testimonial en Colombia recuerda, así, una y otra vez el valor que supone tomar la palabra y comprometerse en cuanto individuo responsable. Fabiola de Lalinde: "La lucha por los derechos humanos en Colombia es una carrera de obstáculos desde todo punto de vista. [...] es un riesgo inmenso. Ya han asesinado cuatro miembros del Comité de Antioquia [...]" (Salazar, 1993, p. 217). Para asumir este yo, más allá del instinto de conservación, se necesita que lo exija una urgencia, provocada por una situación extrema.

Por ser una mujer que cifra su dignidad en el hecho de nunca quedarse callada, Rosalba representa una transgresión de la condición femenina, pero también del estatuto de la víctima, del oprimido y de la gente que se encuentra en medio del conflicto. Un ingeniero que trabaja en unas obras insulta a los desplazados: "Yo no aguanté más y me paré y le dije: 'Mire, señor, así como usted exige respeto, nosotros también se lo exigimos'. [...] todos tenían miedo de hablar" (Franco, Nieto y Rincón, 2010, p. 113). Islena dice lo mismo: "Si me iba a morir, lo haría de pie con la frente en alto, al único que le doblo la rodilla es al Dios de mi vida [...]" (Franco, Nieto y Rincón, 2010, p. 121). Estas voces femeninas están ocupando así, simbólicamente, el espacio de la sociedad civil en medio de la guerra, desde el cual contrarrestar este dictamen: "El que está en el medio es el que pierde" (Rosalba, citada por Franco, Nieto y Rincón, 2010, p. 114). 


\section{LO COTIDIANO}

El testimonio constituye el campo privilegiado de lo cotidiano y sus vivencias, y por ende, de la voz femenina. Al estar ligada a las rutinas de comprar comida, pagar facturas y buscar trabajo, esta pone en evidencia la relación entre terror y cotidiano. Su palabra va narrando esos espacios pisoteados y convulsionados desde ese lado de la realidad, tal como lo viven los pobres, los anónimos, los marginados y los silenciados.

Si en un régimen democrático puede uno vivir sin enterarse de las huelgas o de la política social, es imposible pasar la violencia por alto, cuando se apodera de un país entero, ya que militariza la vida cotidiana. La autobiografía de María Eugenia Vásquez recuerda, así, cómo no hay escapatoria ante una violencia que invade todas las dimensiones del diario vivir, hasta lo más íntimo del ser, para deteriorarlo psíquicamente y generar esquizofrenia y paranoia. Cuenta, de la misma forma, cómo un medio violento obliga a forjarse otra personalidad, al imponer el uso de pseudos que significan comportamientos y percepciones ajenas a las propias, y al dejar a las armas regular las relaciones sociales.

Si se da por sentado que las mujeres son cobardes y débiles para la guerra y que, por tanto, deben quedarse en el ámbito casero, parecerá obvio que sus relatos se caractericen por contar su cotidianidad. Sin embargo, ya sabemos desde hace tiempo que las marcas genéricas no residen en ninguna esencia y que las mujeres pueden ser tan valientes o tan crueles como los hombres. Las estrategias específicas de supervivencia y de enfrentamiento diario al conflicto que ellas narran no se deben tanto a su condición biológica, sino más bien a su papel social. Por ser vinculada culturalmente al campo afectivo y al cuidado de los demás, la mujer colombiana, como Electra, se atreve a hurgar sin cesar los rastros de sus muertos. Así, Rosalba, con el cadáver de su hermano: "Visité casi todos los cementerios de las poblaciones cercanas. También buscaba entre los cadáveres que aparecían en la carretera" (Franco, Nieto y Rincón, 2010, p. 109).

En medio de unas 24000 muertes violentas al año, y en una situación de guerra, el yo femenino relata un cotidiano desquiciado, en el que el tiempo se mide por la intensidad del instante y el espacio se compartimenta y se desarticula, ya que ocuparlo eficazmente significa imponer su ley mediante el terror e invadir hasta lo más íntimo de la vida. Cuando los paramilitares invaden a la comuna 13 (Medellín) y operan de noche, encapuchados y vestidos de camuflado, el yo ya no puede controlar su espacio ni organizar su diario vivir. Cuando el enfrentamiento se generaliza y se da calle a calle, casa a casa, hasta el sueño está invadido. Gloria Posada cuenta:

Nunca imaginamos que [...] la explosión de granadas, el zumbido de las balas, el estallido de las bombas, el humo, se convertirían en paisaje cotidiano, diurno y nocturno, en alarma para despertar en la madrugada, en señal para resguardarse en casa, en interrogación sobre el irse y abandonarlo todo, o quedarse y esperar el transcurso de las horas. (Posada, 2007, pp. 2-3)

Este terror cotidiano instaura la vivencia de un tiempo parametrado por el miedo, medido y calculado en función de la muerte. Amenazan a Islena y le dan un plazo de diez años de vida: "Yo, voy a cumplir diez y medio, y aún estoy viva [...]. A esta altura creo que con todo lo que me han hecho no me voy a morir en esas circunstancias. Uno aprende a convivir con el miedo..." (Franco, Nieto y Rincón, 2010, p. 123). Este contexto del sobrevivir al día impone replantearse las relaciones afectivas y la vida, dándoles nuevos contenidos. Islena siente culpabilidad ante su hija por lo que le hace vivir, pero afirma: "Yo estaba amando la muerte -no tenía otra opción- y estaba muy tranquila. Cuando me acostaba dormía profundamente, sin 
sobresaltos. Siempre me despertaba puntualmente y me alegraba de estar viva" (Franco, Nieto y Rincón, 2010, p. 121).

Ya se analizó cómo la cultura del miedo (Bermúdez-Gallegos, 1990, p. 465) impuesta durante la dictadura en Argentina (1976-1983), alteró el equilibrio social y las relaciones entre esfera pública y privada, desarticuló el discurso y destruyó lo cotidiano, al interrumpir "los canales de transmisión de la experiencia" y "las redes de la memoria colectiva" (p. 465). En semejante contexto, contar su historia le permite al yo apropriarse de nuevo de un tiempo y de un espacio fraccionados y desarticulados. Vuelve a ser el centro organizador de lo que, por más nimio y parcial que sea, constituye el espacio vital de la supervivencia: el barrio, la calle, el cuarto, la cama:

Para cuidarse de las heridas, había que pensar dónde estar en la habitación, en el baño, en la cocina... Medir la altura de la cama, y dormir y levantarse nuevamente, salir al trabajo o al estudio, hacer las compras, pagar los servicios públicos y los impuestos, y regresar a la casa para que la vida siguiera su curso. (Posada, 2007, p. 3)

La práctica testimonial ofrece, así, la posibilidad de volver a tejer lo cotidiano mediante el discurso. María Eugenia Vásquez cuenta que después de la muerte de un compañero a quien quería mucho:

[...] sentía que no podía dejar inconclusa la tarea de contar esta historia. De ahí en adelante empecé a ponerme pequeños plazos y pequeñas metas que me permitieron salir lentamente del letargo. Fijar la vida a largo plazo para nosotros es difícil, porque somos gentes sin futuro, aprendimos a vivir al menudeo. (Salazar, 1993, p. 370)

La fuerza de esta escritura radica no solo en una experiencia que debe ser contada, sino también en la vida misma. Poder volver a crearse en el diario vivir es darse "pequeños plazos y pequeñas metas" que permiten reconstruir una identidad y seguir viviendo. Este yo femenino es, así, el de una memoria que vive y se transforma en y por la escritura y se puede proyectar hacia un futuro cercano mediante un cotidiano en el que el yo se acepta a sí mismo. La palabra, justificación contemporánea del pasado, le abre la vía a un presente que no está del todo apaciguado, pero que sí puede asumir sus vivencias. Para María Eugenia Vásquez, se trata de aceptar la muerte de un hijo criado por otros para dedicarse a la guerrilla; Vera Grabe, a su vez, busca justificar ante los ojos de su hija la ausencia de una madre guerrera. En esta necesidad de dominar el tiempo y de superarlo para sobrevivir, la palabra realiza un deber con el presente, sobreponiéndose a este pasado que no pasa y aguarda por volver.

\section{LA MEMORIA Y LA PAZ}

“¿No estoy todavía en vida? Vida miserable, ya lo sé, pero que a mí, me basta. Y, por otra parte, soy el tormento de los culpables, y este es un homenaje que, así, le rindo al muerto [...]" (Sófocles, 1972, p. 151). Como Electra, el yo testimonial femenino reivindica obrar por la transmisión y la preservación de la memoria y por tomar la palabra para que lo contado no vuelva a ocurrir. Las formas autobiográficas le permiten a la vez descubrir el lugar de su historia en la Historia, y hacer emerger recuerdos y vivencias tanto individuales como sociales. Lo que demuestran, así, estos yoes testimoniales femeninos es que el yo es una memoria, inseparable de un discurso y de una serie de representaciones, las cuales no se elaboran de manera individual. Mediante la escritura, María Eugenia Vásquez entendió que más allá de lo psicológico, está lo social y que identidad, pasado, memoria y grupo no se pueden desvincular: 
De una cosa que no fui consciente hasta que terminé el libro fue de cómo utilizar mi historia para contar la historia de la organización [sic] me iba a fortalecer tanto como mujer y me iba a dar la posibilidad de construir una identidad distinta de la que construí a partir de mi militancia. (Hoyos, 2003, p. 2)

Las diversas etapas de conciencia y de percepción crítica de los hechos que se narran mediante esta escritura parten, así, de una subjetividad que desemboca en una ética, una estética y una política. Se trata de una memoria de combate que busca, por una parte, llegar a las otras memorias para transformarlas $y$, por otra, se presenta como resistencia, resistencia al olvido, herramienta para superar los escollos contra los cuales la historia de Colombia choca sin cesar para terminar repitiendo situaciones de enfrentamiento entre bandos e intereses opuestos. Esta memoria se convierte en lucha contra la mentira y la resignación. Es lo que explica F. de Lalinde cuando consigue por fin la exhumación de los restos de su hijo:

Mi Operación Cirirí logró por fin que la maquinaria recobrara la memoria y que se organizara ese operativo. Ese fue el resultado de 2747 días de lucha minuciosa [...] en la que no traicioné mis convicciones de mujer creyente y amante de la democracia, pero donde tampoco transigí con quienes en este país creen que a las personas se les puede tratar como a cualquier cosa por ser de un bando distinto. Le abrí un hueco a la maraña de embustes y de olvidos. (Salazar, 1993, p. 227)

El yo testimonial colombiano establece, así, una equivalencia entre memoria y paz. Desde su cotidiano estas voces femeninas están buscando, en efecto, construir un país en paz ya que, como lo afirma Guillermo González (2002): "La paz no se hace con adjetivos, sino yendo a las raíces de la guerra [...] y conociendo a los que la hacen a diario" (pp. 21-22). Todas mencionan este tema en sus relatos y no está de más recordar la especial implicación de las asociaciones de mujeres en las múltiples iniciativas y marchas por la paz en los últimos veinte años.

En esta cultura patriarcal colombiana, la experiencia de las mujeres está ligada directamente, en efecto, a la exclusión, el rechazo y la alteridad. Por una parte, y más allá de los estereotipos que representan el género femenino como naturalmente bondadoso, protector y dedicado al cuidado de los demás, el yo femenino -como el masculino- resume a los demás, es decir, a su grupo social y su manera de concebir ese yo. Los discursos de Marta Luz Henao, la juez, de la Chiqui o los de Vásquez demuestran de esta forma que todos somos hechos de discursos de género diferente y que en cada yo está el otro, los otros. La escritura autobiográfica constituyó así para V. Grabe (2000) un medio para identificar el machismo, tanto el "de los hombres como [el] que teníamos incorporado" (p. 354).

Por otra parte, la escritura testimonial femenina constituye un campo de observación privilegiado de la noción de alteridad y de su experiencia cotidiana. Construir una identidad femenina propia significa, en efecto, enfrentarse con la interiorización de la imagen sociocultural construida por y en función de la mirada masculina. Encontrarse consigo misma es encontrarse con esa alteridad que constituye toda mujer para una mujer. Construir una identidad en femenino implica, así, admitir la presencia de esa imagen otra en sí y admitirla en la otra y en la semejante: las otras mujeres. Conocernos es reconocernos mutuamente en cuanto sujetos, e instaurar el diálogo: "La historia de la mujer está plagada de silencios. Silencios creados por la imposibilidad de visualización del hombre. La cárcel me posibilitó un encuentro con la mujer, con su naturaleza, con sus angustias [...]" (Grabe, 2000, p. 123). En este trabajo de reflexión sobre la alteridad propuesto en sus relatos autobiográficos, todas construyen, así, un yo que se opone al uds., las mujeres y a la socialización de lo biológico, con sus representaciones tópicas de un deber ser, de un deber aparentar y de un deber hablar asignadas al género femenino. 
Los relatos femeninos colombianos son de especial relevancia en este aspecto, ya que muchos provienen de excombatientes o de mujeres para quienes la imagen de la guerrera forma parte de su entorno. Esta encarna, en efecto, la transgresión máxima a las oposiciones culturales fundamentales entre los géneros: hace verter voluntariamente la sangre como los hombres y ya no la mira fluir pasivamente de su propio cuerpo. El hecho de que una mujer testimonie sobre hechos históricos controvertidos representa en sí otra transgresión, ya que etimológicamente testigo viene de testes (testículos) y en la Roma antigua solo podían dar testimonio los que los tenían sanos y bien hechos. La transgresión que operan las voces femeninas frente al sentido de testimoniar subraya con esta exclusión etimológica los mecanismos utilizados para silenciarlas. Desde el campo que les es cultural y socialmente reservado, lo cotidiano, sus palabras destejen los mecanismos de las memorias oficiales y del poder, y revelan cómo se construyen situaciones y comportamientos de exclusión y de enfrentamiento.

\section{TEJER LO SOCIAL}

La escritura testimonial en general demuestra que en el intercambio de subjetividades con ese otro que lo escucha, el yo no existe sin el tú. La circulación de la palabra testimonial busca, de manera declarada, volver a crear unos lazos sociales y unas solidaridades en unas circunstancias adversas. María Eugenia de Antequera (viuda de un dirigente de izquierda asesinado) relata el acercamiento entre las mujeres que tienen a un ser querido desaparecido, cuando la madre de un soldado recibe el cadáver de su hijo:

Nunca podré olvidar su gemido de madre adolorida...

Yo no veía que a esas señoras la muerte de quienes amaban les doliera más ni menos que a mí. Hasta ese momento, yo pensaba que en la guerra solamente habíamos sufrido los civiles y los de izquierda. Pero ese día sentí el dolor de los otros, ese dolor que no había visto o que no había querido ver. Entonces, me di cuenta de que el dolor es igual para todos (Lara, 2000, p. 207).

La forma misma del relato testimonial permite volver a tejer simbólicamente nuevas solidaridades entre clases. A semejanza de las diversas voces que se entrelazan en el texto, diversos estratos sociales (representados por el mediador letrado y los testigos) colaboran, en efecto, en esta escritura para reconstruir coralmente una comunidad que hay que volver a edificar urgentemente. Mediante la palabra y la escritura, estos relatos proponen un modelo de posibles coexistencias en otros terrenos. Patricia Lara dedica así su libro: "A cada una de las mujeres que aceptaron contar su historia, [...] con el fin de construir este libro y empezar a dibujar con él esa Colombia en paz donde podamos ser buenas vecinas" (p. 10). De esta forma, la escritura testimonial se da por misión ser un lazo que permita volver a construir redes sociales, al contar una historia tanto individual como colectiva y responde, así, a lo que el filósofo Jesús Martín-Barbero (entrevista personal, 2005) afirma ser hoy tarea apremiante para Colombia: articular nación y 're'-narrar este país.

Daniel Pécaut (2005) estima, por su parte, que Colombia nunca ha podido elaborar "una simbología nacional capaz de hacer que todos se sintieran miembros de una misma comunidad política" (p. 2). Las diversas prácticas testimoniales constituyen, así, el intento, llevado desde diversos sectores de la sociedad, de construir a pedazos un relato de la violencia, con el fin de no convertirla en pasado que no pasa. Se trataría de remediar, a partir de las invariantes que se desprenden del conjunto de los relatos, esta carencia de simbología nacional, para que todos puedan sentirse miembros -aun en el dolor y en el luto- de la misma 
comunidad histórica. Y esta solo podrá elaborarse al aceptar que "mi pasado se parecía a los caminos del país, donde una o varias cruces en cada recodo dejan constancia de la muerte" (Vásquez, 2001, p. 16).

Al decir esta violencia y al nombrar lo innominable, el testimonio le abre un universo simbólico y semántico a algo que no ha sido expresado hasta ahora. De esta forma, transforma la violencia en discurso y establece un diálogo entre sectores que se autorrepresentan como incomunicados entre sí. Construye de esta forma uno de "esos espacios de mediación [que] tuvieron un papel esencial en la historia" (Gruzinski, 1999, p. 43) y que ofrecen lugares compartidos de reflexión, al hacer aflorar unas experiencias semejantes, mediante la coexistencia de relatos opuestos. Al poner en evidencia unas constelaciones de representaciones afines entre los diversos bandos, el espacio testimonial supera la dicotomía sociopolítica y la polaridad blanco/negro, para dejar paso a los grises, en los cuales se sitúan las víctimas estructurales.

El contenido simbólico de la escritura testimonial es más poderoso todavía. Su fuerza institucional y su papel de lazo social residen en su impacto humano "en la medida en que parte de la confianza en la palabra del otro" (Ricoeur, 2000, p. 207). En efecto, la confianza en la palabra del otro refuerza "la semejanza en humanidad de los miembros de la comunidad. El intercambio de confianzas especifica el lazo entre seres semejantes" (p. 207). Dar y recoger testimonios es estar convencido de que esta semejanza en humanidad puede restaurar los valores colectivos.

El conjunto de los diversos relatos autobiográficos escritos por las mujeres en Colombia construye, así, una polifonía en la que lo individual y lo personal se desvanecen para dar paso a una coralidad social. Hacer vivir la memoria significa, para cada cual, recuperar su historia y su identidad, es decir, su dignidad. Y en este proceso, cada quien se convierte en una Electra que clama por la justicia y el derecho a llorar y a enterrar a sus muertos. Pero cada una es al mismo tiempo un miembro del coro que comenta y comparte la indignación, los duelos y los dolores de todas las Electras que, con ella, levantan cabeza y se atreven a alzar la voz.

\section{REFERENCIAS BIBLIOGRÁFICAS}

Bermúdez-Gallegos, M. (1990). The Little School por Alicia Partnoy: el testimonio en la Argentina. Revista Iberoamericana, 151, 463-476.

Estripeaut-Bourjac, M. (2012). L'Écriture de l'urgence en Amérique Latine. Bordeaux: Presses Universitaires de Bordeaux.

Franco, N., Nieto, P. y Rincón, O. (eds.). (2010). Tácticas y estrategias para contar. Bogotá: C3 FES.

González, U. G. (2002). Los niños de la guerra. Bogotá: Planeta.

Grabe, V. (2000). Razones de vida. Bogotá: Planeta Colombiana.

Gruzinski, S. (1999). La Pensée métisse. París: Fayard.

Hoyos, S. (2003). Ecos de la guerra en palabras de mujer. Revista número, 29. Recuperado de revistanumero. com/29ecos.htm.

Lara, S. P. (2000). Las mujeres en la guerra. Bogotá: Planeta Colombiana.

Lejeune, P. (1973). Le pacte autobiographique. Poétique, IV, 137-162.

Lejeune, P. (1980). Je est un autre. París: Ed. du Seuil.

Luna, R. (2010). Mi dignidad, mi dignidad vale más que todo lo que se perdió. En N. Franco, P. Nieto y O. Rincón (eds.). Tácticas y estrategias para contar (pp. 105-115). Bogotá: C3 FES. 
Pécaut, D. (2005). Un mayor compromiso con este país. Recuperado de argumentosydebates.univalle.edu.co/2000/ anexo3.htm.

Posada, G. (2007). Comuna 13. Sin publicar.

Rey, I. (2010). Amo la vida, también a la muerte. En N. Franco, P. Nieto y O. Rincón (eds.), Tácticas y estrategias para contar (pp. 117-124). Bogotá: C3 FES.

Ricoeur, P. (2000). La mémoire, I'histoire, l'oubli. París: Ed. du Seuil.

Salazar, A. J. (1993). Mujeres de fuego. Medellín: Corporación Región.

Sófocles. (1972). Électre. Tomo 2. París: Les Belles Lettres.

Vásquez, P. M. E. (2001). Escrito para no morir. Bogotá: Coproducción ILSA, Ediciones Antropos, Ministerio de Cultura. 